\title{
DISTRIBUTION OPTIMIZATION MODEL: A CASE STUDY OF MOBILE HANDSET DISTRIBUTION SYSTEM
}

\author{
Devi Prasad Ghosh ${ }^{1 *}$ \\ *l Head of Marketing Department, Institute of Management Technology (IMT), Hyderabad. \\ Director, Graph Matrix Digital Solutions, Hyderabad Email: devghosh@imthyderabad,edu.in \\ /dpghosh@graphmatrixsolutions.com /dp_ghosh@yahoo.com \\ Mobile: +919324705051
}

\section{*Corresponding Author: -}

Email:devghosh@imthyderabad,edu.in

\begin{abstract}
: -
The objective of the paper was to develop a decision making tool that mobile handset distribution company could use to derive a more efficient and effective distribution of handsets to its channel. The paper developed the problem definition, the formulation of LP model, the procedure is designed as a solution to the problem, and the outcome as benefits to the company is presented. Linear programming model is formulated that can be solved using commercial software. This paper demonstrates the potential for using linear programming in managing large-scale transportation and distribution problems. The model resulted in the creation of new metrics for measuring the performance, the model will help the company understand conditions that result in inventory shortages, and the model lead to the discovery of inefficiencies in company distribution strategy. The model is directly beneficial to any company in Mobile Handsets distribution. With a large proportion of handsets sales is accounted by online retailers direct to customers, the distribution of handsets not only defines the cost but also customer satisfaction by managing delivery time and return-of-handsets offer. The model is also applicable for cases in other industries which operates in multiple markets and have large variety of Stock Keeping Units (SKUs).
\end{abstract}

Keywords: Distribution Optimization Model. Strategic Planning. Transportation Optimization Model. Mobile Handsets Distribution. Sales \& Distribution strategy.

\section{(우 $($ (1)}




\section{INTRODUCTION}

The purpose of formulating and optimizing the distribution model for handset distributors do provide company with a means for comparing their strategy for moving pallets of handset through their distribution network with the optimized strategy derived from the formulated model. Such analyses usually lead to a more economical distribution strategy. Therefore, the first objective of the paper was to establish the scope of the model by identifying the aspects of the company distribution that would be studied. The second objective was to define the decision variables, parameters, constraints and performance measures necessary for formulating a model of company handset distribution operations. The third objective was to formulate a linear programming model for the sales \& distribution strategy and planning. And the fourth objective was to help analyze the optimized distribution of handsets determined by the model and identify improvements to the existing handset sales \& distribution strategy used by the company.

Being an employee associated with Handset business of the company helped in establishing the problem definition (project scope); defining the model's decision variables, parameters, constraints, and performance measures; validating the model formulation; providing input parameters for the model; and defining and analyzing test scenarios. The close involvement with the process helped in quantifying the variables and relationships, which drive handset distribution and identifying areas for additional data collection and study.

\section{THE COMPANY}

Reliance Group, an offshoot of the Group founded by Shri Dhirubhai H Ambani (1932- 2002), ranks among India's top three private sector business houses in terms of net worth. The group has business interests that range from telecommunications (Reliance Communications Limited) to financial services (Reliance Capital Ltd) and the generation and distribution of power (Reliance Infrastructure Limited).

Reliance Group's flagship company, Reliance Communications, is India's largest private sector information and communications company, with over 150 million subscribers. It has established a pan-India, high-capacity, integrated (wireless and wireline), convergent (voice, data and video) digital network, to offer services spanning the entire infocomm value chain.

Reliance Communications offer a complete range of telecom services, covering mobile and fixed line telephony including broadband, national and international long-distance services, data services and a wide range of value added services and applications across all Telecom circles in the country.

\section{PROBLEM DEFINITION}

The company is following currently Hub and Spoke distribution model. The country is divided into four regions East, West, North \& South. Calcutta, Mumbai, Delhi \& Chennai airport act as gateway of import of handsets for respective region from foreign manufacturers. Warehouses at Kolkata, Mumbai, Delhi and Chennai acts as Regional Hub Warehouse. States warehouses falling under a region are serviced for all products through this Regional Hub warehouses. This distribution model is designed based on operational convenience of the company and not on scientific method of market demand or cost efficiency of distribution. In the first instant, we can conclude that the Hub and Spoke model in the current form described here may fulfill administrative requirements based on geography control, but may not be the optimum model for distribution of handsets. Moreover, this does not take into account the advantages of transshipments model where inter warehouses transfer or high value products with limited demand can be shipped as per market need.

The company currently markets many handset models. Because each variety of handset models have different Sizes, different Prices, has different Demand and Cost, they are treated as separate products (SKUs) in the model. The data for 18 varieties of Handsets model provided here is used as a representation for the understanding of the model. (Table 1)

Company has warehouses in every state throughout the country that are used to store and distribute the company product. For the purpose of this project, it was decided that 18 locations of state warehouses would be included in the model. Also, only handset product and not handset accessories will be considered for the study as it constitutes more than $80 \%$ of the logistic operations cost of the company. The locations of the state warehouses are provided. (Table 2)

The procurement and distribution of Handsets is a dynamic activity. The procurement and distribution activities are indexed over time in the model. The model must take into consideration the planning horizon of the company. The term time bucket was used to describe a 1-month period. The sales period for the company is 12 months (April to March), that is 12-time buckets. Demand and procurement quantities are based on state team sales estimates for the year that decrease in validity over extended planning horizons. The model takes into account the procurement planning horizon of 3 months followed by the company. The shorter planning horizon increased the accuracy of the forecasted input data. Therefore, the estimates in the model need to be updated after every quarter for subsequent quarter to improve the accuracy of the model.

The pallet was used by the company as a unit to count the movements of handset boxes. Company generally collects and records data on No. of Units per model basis, but Handsets is almost always procured and distributed in full pallets (50 Boxes per pallet).

The model indicates appropriate decision's regarding moving pallets of Handsets between Warehouses. The model recorded the ending inventory, sales and lost sales for every time period. These quantities are available in No. of units but needed to be reported in pallets. 
In order to facilitate model development, Company need to estimate several physical and financial parameters. The physical parameters include beginning inventory levels, procurement levels and demand levels for each SKU (indexed by time bucket where appropriate), as well as storage capacities for each state warehouse. Company also need to estimate the financial parameters include selling price as well as shipping, handling and storage costs. All financial parameters were measured on a per pallet basis (or per pallet per time bucket).

Based on general company practice, four key assumptions were made for handset procurement and distribution. First, demand and procurement forecasts made were accurate. Second, transportation cost could be captured on a per pallet basis. Third, adequate supply of trucks is always available for transportation. Fourth, fractional pallet values are not captured in the model. All of these assumptions are necessary to simplify the model. A simpler model would be beneficial for this study for easier understanding of the reader and practitioners for implementation.

\section{LINEAR PROGRAMMING MODEL FORMULATION}

The first step in formulating the linear programming (LP) model is to establish the indexes over which the variables and parameters of the model will be defined. The indexes are Handset model SKU, State Warehouse and time bucket.

$$
\text { Handset Type (SKU): } \quad S=1,2, \ldots \ldots, 18 \ldots \ldots \text { s (Table } 1)
$$

State Warehouse: $\quad W=1,2, \ldots, 18, \ldots . . \mathrm{n}$ (Table 2)

Time bucket: $\quad T=1,2,3, \ldots \ldots 12 \ldots \ldots \ldots t$

Having defined these indexes, the next step is to identify the variables included in the model. These variables include the decision variables and other output variables.

The decision variables in this model capture the movement of handsets among company warehouses. Therefore, the decision variables are:

$n P_{s i j t}$ The number of pallets of SKU $s$ delivered from state warehouse i to state warehouse $j$ in time bucket $t$.

The output variables are end inventory, sales, lost sales at the state warehouse.

Therefore, the output variables are:

$n I_{s i t}$ The number of pallets of SKU $s$ remaining in inventory at state warehouse $\mathrm{i}$ at the end of time bucket $t$

$n S_{\text {sit }} \quad$ The number of pallets of SKU $s$ sold at state warehouse $i$ during time bucket $t$

The number of pallets of SKU $s$ that were not available for sale upon demand at state warehouse $\mathrm{i}$

$n L S_{\text {sit }}$ during time bucket $t$

The input parameters for the model include the physical and financial parameters. The physical parameters are: $n I_{s i t-1}$ The number of pallets of SKU $s$ in Inventory at state warehouse $i$ prior to the time bucket $t$.

$n S C_{i} \quad$ The number of pallets of storage capacity of state warehouse $i$.

$n S h_{s i t} \quad$ The number of pallets of SKU $s$ at state warehouse $i$ that become available for Shipment during time bucket $t$

$n D_{s i t} \quad$ The number of pallets of Demand for SKU $s$ at state warehouse $i$ during time bucket $t$.

The cost parameters are:

$S P_{s i} \quad$ The selling price of a pallet of SKU $s$ at state warehouse $\mathrm{i}$

$C t_{i j} \quad$ The cost to transport one pallet from state warehouse $i$ to state warehouse $j$

$C h_{i} \quad$ The cost for handling one pallet at state warehouse $i$

$C s_{i} \quad$ The cost to store one pallet at state warehouse $i$ for one time bucket

The model objective is to identify the most efficient decisions regarding the distribution of pallets of Handsets. Therefore, the objective function was defined to maximize the profit margin that is the difference of sales revenue generated and the costs for shipping, handling and storage.

Maximize

$$
\sum_{s=1}^{18} \sum_{i=1}^{18} \sum_{t=1}^{12} S P_{s i} n S_{s, i, t}-\sum_{s=1}^{18} \sum_{i=1}^{18} \sum_{j=1}^{18} \sum_{t=1}^{12}\left(C t_{i, i}+C h_{i}\right) n P_{s, i, i, t}-\sum_{s=1}^{18} \sum_{i=1}^{18} \sum_{t=1}^{12} C s_{s, i, t} n I_{s, i, t}
$$

There are several functional relationships, which limit the values that can be taken on by the decision and output variables. The first of these relationships requires that balance be maintained between pallets input to a state warehouse during a time bucket (initial inventory, shipments in from state warehouse, new procurement from suppliers or imports), pallets sent out of a state warehouse during a time bucket (shipments out, sales), and ending inventory.

$$
n I_{s i, t-1}+\sum_{i=1}^{18} n P_{s, i, j, t}+n P_{s, i, t}-\sum_{i=1}^{18} n S h_{s, i, j, t}-n S_{s, i, t}=n I_{s, i, t} \quad \forall s, i, t
$$

The ending inventory for time bucket $\mathrm{t}-1$ corresponds to beginning inventory for time bucket $\mathrm{t}$.

$$
n I_{s, i, t-1}=\text { beg }_{-} n I_{s, i, t} \quad \forall s, i, t
$$


The second functional relationship states that the total inventory at a state warehouse be at or below the capacity of that circle warehouse.

$$
\sum_{s=1}^{18} n I_{s, i, t} \leq n S C_{i} \quad \forall i, t
$$

The third functional relationship states that all demand is accounted for by either a sale or a lost sale.

$$
n S_{s, i, t}+n L S_{s, i, t}=n D_{s, i, t} \quad \forall s, i, t
$$

Adding non-negativity constraints for each of the decision and output variables yields the final formulation.

Maximize

$$
\sum_{s=1}^{18} \sum_{i=1}^{18} \sum_{t=1}^{12} S P_{s} n S_{s, i, t}-\sum_{s=1}^{18} \sum_{i=1}^{18} \sum_{j=1}^{18} \sum_{t=1}^{12}\left(C t_{i, j}+C h_{i}\right) n P_{s, i, j, t}-\sum_{s=1}^{18} \sum_{i=1}^{18} \sum_{t=1}^{12} c s t_{s, i, t} n I_{s, i, t}-\sum_{s=1}^{18} \sum_{i=1}^{18} \sum_{i=1}^{18} \sum_{t=1}^{12}\left(C t_{i, j} * n P_{i, j}\right)
$$

s.t.

$$
\begin{array}{ccc}
n I_{s, i, t-1}+\sum_{i=1}^{18} n P_{s, i, j, t}+n P_{s, i, t}-\sum_{i=1}^{18} n P_{s, i, j, t}-n S_{s, i, t}=n I_{s, i, t} & \forall s, i, t \\
\sum_{s=1}^{18} n I_{s, i, t} \leq n S C_{i} & \forall i, t \\
n S_{s, i, t}+n L S_{s, i, t}=n D_{s, i, t} & \forall s, i, t \\
n P_{s, i, j, t} \geq 0 & \forall s, i, j, t \\
n I_{s, i, t} \geq 0 & \forall s, i, t \\
n L S_{s, i, t} \geq 0 & \\
n S_{s, i, t} \geq 0 & \forall s, i, t
\end{array}
$$

Above formulation is a linear programming problem having multiple variables and multiple functional constraints. The matrix below represents the transportation cost between state warehouse $\mathrm{i}$ and state warehouse $\mathrm{j}$ for number of handset pallets $\mathrm{nPi}$

\begin{tabular}{|l|l|l|l|l|l}
\hline $\begin{array}{l}\text { State Warehouses } \\
\text { ( i j) }\end{array}$ & $\mathrm{W}_{1}$ & $\mathrm{~W}_{2}$ & $\mathrm{~W}_{3}$ & $\mathrm{~W}_{\mathrm{j}}$ & Total Handsets \\
\hline $\mathrm{W}_{1}$ & $\mathrm{Ct}_{11}$ & $\mathrm{Ct}_{12}$ & $\mathrm{Ct}_{13}$ & $\mathrm{Ct}_{1 j}$ & $\mathrm{nP}_{1}$ \\
\hline $\mathrm{W}_{2}$ & $\mathrm{Ct}_{21}$ & $\mathrm{Ct}_{22}$ & $\mathrm{Ct}_{23}$ & $\mathrm{Ct}_{2 \mathrm{j}}$ & $\mathrm{nP}_{2}$ \\
\hline $\mathrm{W}_{3}$ & $\mathrm{Ct}_{31}$ & $\mathrm{Ct}_{32}$ & $\mathrm{Ctt}_{33}$ & $\mathrm{Ct}_{3 \mathrm{j}}$ & $\mathrm{nP}_{3}$ \\
\hline $\mathrm{W}_{\mathrm{i}}$ & $\mathrm{Ct}_{\mathrm{i} 1}$ & $\mathrm{Ct}_{\mathrm{i} 2}$ & $\mathrm{Ct}_{\mathrm{i}}$ & $\mathrm{Ct}_{\mathrm{ij}}$ & $\mathrm{nP}_{\mathrm{i}}$ \\
\hline Total Handsets Pallets & $\mathrm{nP}_{1}$ & $\mathrm{nP}_{2}$ & $\mathrm{nP}_{3}$ & $\mathrm{nP}_{\mathrm{j}}$ & $\sum \mathbf{n P}_{\mathbf{j}}$ \\
\hline
\end{tabular}

\section{SOLUTION AND IMPLEMENTATION}

Having formulated the distribution problem as a linear programming problem, the next step in the project is to select a method of performing the optimization. LINGO (developed by LINDO Systems, Inc.) is a suitable for use and readily available. It permits the use of spreadsheets for reading the values of input parameters and output variables. The input and output spreadsheets data for the model are provided by the company. For the purposes of debugging and testing the LINGO code, a test problem can be defined.

Once the LINGO code is verified, company input data can be used for implementation.

\section{MANAGERIAL USE}

The output of the model can be compared to the actual decisions to identify weaknesses in any distribution strategy. The process of formulating the model, developing test scenarios, and making these comparisons can provide valuable benefit to the company.

In fact, six key benefits of the model that can be identified are as below:

1. The model input required that company project availability for shipment on a product variant (SKU) basis. Company had to analyze work order completions and add the one month target release cycle to determine projected production availability for shipping schedule creation. Company currently does not capture data as a formal report or tool in place; however, company recognized a need and the potential value for such data reporting.

2. The model can calculate projected revenues from sales that were shipped to meet demand based upon the selling price on a variant basis. The model can also calculate costs for freight, handling and storage. Company will be able to 
create a ratio of shipping, handling and lease costs as a percentage of revenue. Company has not historically performed this comparison in their business; however, it is a valuable measure.

3. The model calculates "lost sales" $\square$ units of sales lost due to inventory unavailability in the desired time bucket or freight costs in excess of revenue from sale. In reality, company as a practice never holds a truck or misses a sale because the revenue may not exceed the freight costs. However, this information will be tremendously valuable as company can use it to analyze why inventory was not available or available closer to the point of sale. The model does provide information to distinguish which situation (unavailable or prohibitive freight cost) created the lost sale situation.

4. The model assigns demand to a specific state warehouse. All transportation orders dispatched to assigned state warehouse are assumed as demand for the state. This concept of assigning demand for particular SKU's to specific state warehouse forces sales team to improve the accuracy of demand forecast for the company.

5. The decision to run "actuals" (real data) through the model will prove to be a beneficial exercise for company. This model will for a model of benchmark of cost optimization for handset logistic between state warehouses. Also, the potential to report inaccurate numbers can be corrected due to review of model output.

6. The cost information is likely to reinforced two things: (1) validation for company freight account structure, and (2) necessity of cost-sensitive measures and goals.

7. This model is will also help reduce inventory holding in regional hub warehouses.

8. It will also help in planning movement of non-moving stocks in various state warehouses to other state warehouses where demand for the product exists.

\section{CONCLUSIONS}

The process of formulating the model, testing the model, and analyzing the model's results will provide valuable insights to the company. The company can decide based on the model, focus areas on their transportation and distribution processes. The implementation of the changes based on the model will result in significant cost saving due to reduction in movement of handsets. The handset movement reduction based on the model will help improve the efficiency of the distribution system and ability of the company to improve availability of the products in the right market at right time.

Table 1: Mobile Handset Models SKUs

\begin{tabular}{|l|l|l|l|}
\hline S.No. & Handset Vendor & S.No. & Handset Model \\
\hline 1 & LG RD 2230 & 10 & $\begin{array}{l}\text { LG RD 7230 - - Smart Video Colour Camera } \\
\text { Phone }\end{array}$ \\
\hline 2 & LG RD 2030 & 11 & LG RD 6130 - Colour Phone with Camera \\
\hline 3 & LG RD 2130 & 12 & GTRAN- Standard (without camera) \\
\hline 4 & LG RD 5130 & 13 & GTRAN-Premium (with camera) \\
\hline 5 & LG RD 6000 & 14 & $\begin{array}{l}\text { Samsung SCH A603 - Rotating Colour } \\
\text { Camera Phone }\end{array}$ \\
\hline 6 & LG RD 2130 - Moonlight & 15 & Telson TWC 150 - Colour Watch Phone \\
\hline 7 & Samsung 356 Slim & 16 & Kyocera 7135 - PDA Colour Phone \\
\hline 8 & Samsung SCH - A563 & 17 & Nokia 2280 \\
\hline 9 & Samsung SCH - N191 & 18 & Nokia 3105 \\
\hline
\end{tabular}

Table 2: Company Warehouse Locations:

\begin{tabular}{|l|l|l|l|}
\hline S.No. & Regional Business Unit & $\begin{array}{l}\text { Warehouse } \\
\text { Location }\end{array}$ & States/ City \\
\hline 1 & South & Hyderabad & Andhra Pradesh + Telangana \\
\hline 2 & South & Chennai & Tamil Nadu \\
\hline 3 & South & Bangalore & Karnataka \\
\hline 4 & South & Cochin & Kerala \\
\hline 5 & West & Pune & Maharashtra \\
\hline 6 & West & Mumbai & Mumbai City \\
\hline 7 & West & Bhopal & Madhya Pradesh \\
\hline 8 & West & Bhubaneswar & Orissa \\
\hline 9 & West & Gandhi Nagar & Gujarat \\
\hline 10 & West & Jaipur & Rajasthan \\
\hline 11 & North & Delhi & NCR \\
\hline 12 & North & Chandigarh & Haryana \\
\hline 13 & North & Ludhiana & Punjab \\
\hline 14 & North & Simla & Himachal Pradesh \\
\hline 15 & North & Lucknow & Uttar Pradesh \\
\hline 16 & East & Kolkata & West Bengal \\
\hline 17 & East & Ranchi & Jharkhand \\
\hline 18 & East & Patna & Bihar \\
\hline
\end{tabular}




\section{BIBLIOGRAPHY:}

1. Anderson D.R., Seweeney D.J. \& Williams T.A. (2001). "Quantitative Methods of Business" $8^{\text {th }}$ edition, Thompson South-Western College publishing Bangalore (India), pp 216 - 477

2. Problem definition from distribution system observational study of Reliance Communications Ltd. as an employee. Head (General Manager) - Marketing (Enterprise Wireless \& Devices Business) from May, 2002 to Oct., 2007 at DAKC, Navi Mumbai.

3. Company information from its official website link accessed on 11 $1^{\text {th }}$ Sept, 2013: http://www.rcom.co.in/Rcom/aboutus/overview/overview_reliancegroup.html 